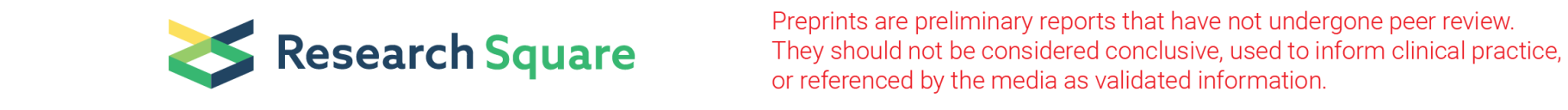

\title{
Using thrombin time to evaluate the efficacy of anticoagulant therapy for acute cerebral infarction
}

\author{
Qianqian Li \\ First Affiliated Hospital of Harbin Medical University \\ Tingjiao Liu \\ First Affiliated Hospital of Harbin Medical University \\ Shanshan Yang ( $\nabla$ yangshanshan81@hrbmu.edu.cn ) \\ First Affiliated Hospital of Harbin Medical University https://orcid.org/0000-0002-4770-9805
}

\section{Research article}

Keywords: argatroban, thrombin time, acute cerebral infarction, anticoagulant therapy, coagulation markers

Posted Date: August 5th, 2020

DOI: https://doi.org/10.21203/rs.3.rs-46163/v1

License: @ (1) This work is licensed under a Creative Commons Attribution 4.0 International License. Read Full License 


\section{Abstract \\ Background}

Although intravenous thrombolysis therapy has been considered as a significant progress in the treatment of acute ischemic stroke, there are limited effective treatments for patients with onset ischemic symptom that beyond six hours during acute ischemic stroke. In this study, we investigated the effectiveness of the intravenous argatroban therapy in acute ischemic stroke patients who cannot be treated with intravenous thrombolysis due to the limited time window.

\section{Methods}

One hundred and eighty patients with acute ischemic stroke that had beyond six hours ischemic symptom were admitted to our hospital and were analyzed retrospectively. Levels of activated partial thromboplastin time (aPTT), prothrombin time (PT) and thrombin time (TT) in peripheral blood of these patients were measured by ELISA at 24 hours post initial therapy.

\section{Results}

We found that plasma TT was significantly prolonged after 24 hours of argatroban treatment. aPTT showed slightly increased prolongation after 24 hours of argatroban treatment. PT also showed slightly prolonged after treatment, however, there was no difference from the basal line. We further investigated the relationship between the level of TT and the clinical effectiveness and safety of intravenous argatroban therapy. We found that when TT was between 40 and 80 seconds, intravenous argatroban effectively promoted the complete recovery rates without increasing the risk of hemorrhage.

\section{Conclusion}

Our study implies that TT assay might be useful for guiding regular dose of agratroban for therapy.

\section{Background}

Acute ischemic stroke (AIS) is the second most common cause of death and the leading cause of disability in China. Intravenous (IV) recombinant tissue plasminogen activator and urokinase thrombolysis have shown to be effective for patients with AIS within six hours of onset [1-3]. However, there are currently no effective and safe treatments for patients with AIS after 6 hours of the onset of ischemic symptoms.

Argatroban is a synthetic direct thrombin inhibitor derived from L-arginine. Argatroban exerts its anticoagulant effects by selectively binding to the activation site of thrombin, which leads to the inhibition of thrombin-induced fibrin formation and platelet aggregation [4, 5]. Previous studies have demonstrated that argatroban could improve regional blood flow and ameliorate neurological deficits without increasing intracranial hemorrhage [6-10]. Compared with heparin, argatroban has a short elimination half-life of approximately 39-51 minutes. Moreover, argatroban has a predictable anticoagulant effect that does not potentiate heparin-induced thrombocytopenia; thus, it causes less bleeding with the same anticoagulant effect [3, 10-12]. LaMonte et al. (2004) reported that argatroban exerted a safe anticoagulant effect in 171 patients with AIS within 12 hours of symptom onset without increasing intracranial hematoma [12]. However, there have been few studies on the application of coagulation markers, including TT for assessing the anticoagulant pharmacological effects in patients with acute cerebral infarction. This study aimed to assess the efficacy and safety of IV argatroban in patients with AIS at $>6 \mathrm{~h}$ after the onset of ischemic symptoms. Moreover, it aimed to evaluate the relationship between TT levels and the clinical effectiveness and safety of IV argatroban therapy.

\section{Materials And Methods}

\section{Patients}

We retrospectively analyzed 180 patients (102 males, 78 females; age < 80 years) with AIS who received IV argatroban treatment between February 2019 and December 2019. These patients were admitted within 48 hours of the onset of symptoms with an NIHSS score of 4-22. All the patients met the diagnostic criteria of cerebral infarction formulated by the Fourth National Cerebrovascular 
Disease conference in 1995. All the patients suffered from mild to severe neurological symptoms, including hemiparesis, hemi-sensory disturbance, dysarthria, hemianopsia, diplopia, and vertigo. The major risk factors for AIS, including hypertension, diabetes mellitus, cigarette smoking, severe alcohol drinking, hyperlipidemia, previous history of stroke, as well as underlying cardiac diseases e.g. atrial fibrillation, were evaluated. All the patients underwent CT or MRI brain scanning before any treatments.

\section{IV argatroban}

For the first two days, argatroban (Novastan, Mitsubishi Pharma Corporation, Osaka, Japan) was administered at a loading dose of 60 $\mathrm{mg} /$ day by continuous IV infusion. This was followed by IV infusion of $20 \mathrm{mg} /$ day in two divided doses over three hours for the subsequent five days. All the patients received oral antiplatelets and IV edaravone along with argatroban treatment. The patients underwent routine CT examinations after the termination of IV argatroban therapy. In the case of neurological deterioration, emergent CT was performed to detect any hemorrhage or progression of infarcted area.

\section{Clinical assessment}

Clinical assessment included vital signs, blood glucose titration, complete blood counts, coagulation profile, NIHSS score, and CT/MRI scanning. A stroke team member obtained the NIHSS scores at admission, at 7 days after initial argatroban treatment, and on the discharge day. The initial stroke severity was analyzed and divided into three categories based on the baseline NIHSS score as follows: mild (0-6), moderate (7-15), and severe (>16). Among the included patients, $46(25.6 \%), 112(62.2 \%)$, and $22(12.2 \%)$ patients were diagnosed with mild, moderate, and severe stroke, respectively. The NIHSS score at admission was compared to the score at 7 days after treatment. The levels of PT, aPTT and TT were measured by enzyme-linked immunosorbent assay.

\section{The criterion of therapeutic effect}

According to the evaluation criteria for the patients with acute cerebral infarction, the therapeutic effect was classified as complete recovery (function defect score decreased by $91 \%-100 \%$ ), remarkable progress (function defect score decreased by $46 \%-90 \%$ ), progress (function defect score decreased by $18 \%-45 \%$ ), no change (function defect score decreased to $<17 \%$ ), and deterioration (function defect score increased by $>17 \%$ ).

\section{Statistical analysis}

The NIHSS, aPTT, PT, and TT values were expressed as mean \pm SD. Pre- and posttreatment values were compared using the unpaired ttest. Between-group comparisons were performed using the chi-square test. Statistical significance was set at $p<0.05$. All statistical analyses were performed using the StatView software (Macintosh version 5.0, SAS Institute).

\section{Results}

We enrolled 180 patients who were treated for deteriorating acute subcortical ischemic stroke. Table 1 presents the baseline characteristics of the patients. The average age of the patients was $63.13 \pm 8.44$ years. Moreover, $43.89 \%$ of the patients were $\geq$ 65 years old while $56.67 \%$ of the patients were male. The median baseline National Institutes of Health Stroke Scale (NIHSS) score was $10 \pm 4$. The median time from onset to IV argatroban was $16 \pm 8$ hours with $44 \%$ of the patients receiving IV argatroban within 12 hours. Further, $20 \%$ and $12 \%$ had moderate to severe middle cerebral artery stenosis and basal artery stenosis, respectively, based on computed tomography (CT) or magnetic resonance imaging (MRI). Furthermore, $25 \%, 12.5 \%, 62.5 \%$ had 0,1 or 2, and 3 risk factors, respectively. 
Table 1

Baseline characteristics of the patients.

\begin{tabular}{|ll|}
\hline Characteristics & Total \\
\hline Case no & 180 \\
\hline Mean age (yr) & $63.13 \pm 8.44$ \\
\hline$<65$ (\%) & $56.11 \%$ \\
\hline$\geq 65$ (\%) & $43.89 \%$ \\
\hline Gender, male (\%) & $56.67 \%$ \\
\hline Risk factor (\%) & \\
\hline 0 & $25 \%$ \\
\hline 1 or 2 & $12.5 \%$ \\
\hline$\geq 3$ & $62.5 \%$ \\
\hline Stroke severity & \\
\hline Mild (NIHSS < 7) & $25.6 \%$ \\
\hline Moderate (7 $\leq$ NIHSS $\leq 15)$ & $62.2 \%$ \\
\hline Severe (NIHSS 815$)$ & $12.2 \%$ \\
\hline Median baseline NIHSS score & $10 \pm 4$ \\
\hline Stenosis of middle cerebral artery & $20 \%$ \\
\hline Stenosis of basilar artery & $12 \%$ \\
\hline Onset to needle time (h) & $44 \%$ \\
\hline$<12$ & $12 \%$ \\
\hline$\geq 12$ & \\
\hline
\end{tabular}

Table 2 shows the values of different coagulate makers before and after argatroban therapy. There was a slightly increased aPTT prolongation after $24 \mathrm{~h}$ of argatroban treatment, which was $44 \%$ greater than the pretreatment value. Moreover, there was PT prolongation at 24 hours after initial treatment; however, there was no significant difference with the baseline value. Plasma TT were significantly prolonged after therapy. The mean values before and after 24 hours of treatment with argatroban were $17.25 \pm 2.64$ and $56.73 \pm 24.18$, respectively.

Table 2

Values of different coagulation makers before and after agatroban therapy.

\begin{tabular}{|lll|}
\hline & Before therapy & 24 h after agatroban therapy \\
\hline TT & $17.25 \pm 2.64$ & $56.73 \pm 24.18^{*}$ \\
\hline aPTT & $25.71 \pm 2.45$ & $37.03 \pm 6.29 *$ \\
\hline PT & $10.80 \pm 0.60$ & $11.46 \pm 0.35$ \\
\hline
\end{tabular}

$* p<0.05$, compared with initial value before therapy.

The mean NIHSS scores after or before 7 days of treatment with argatroban were $10 \pm 4$ (range: 4-22) and 6.98 \pm 3.88 (range: 0-16), respectively. Among the included patients, 44 (24.44\%) patients showed complete recovery, 61 (33.89\%) patients showed remarkable progress, 32 (17.78\%) patients made progress, 28 (15.56\%) patients showed no change, and 15 (8.33\%) patients worsened after treatment with argatroban. Taken together, the total effective rate was $76.11 \%$. Further, $72,96,12$, patients with plasma TT were tested 
within $40 \mathrm{~s}$ (Table 3, group a), 40-80 s (Table 3, group b), and > $80 \mathrm{~s}$ (Table 3, group c). In group a, the mean NIHSS score decreased from $10.01 \pm 3.86$ to $7.92 \pm 4.45$ at 7 days after argatroban treatment. Moreover, 16 (22.22\%), 22 (30.56\%), 10 (13.89\%), 17 (23.61\%), and 7 (9.72\%) patients showed complete recovery, remarkable progress, progress, no change, and worsening after treatment with argatroban, respectively. Taken together, the total effective rate was $66.67 \%$. In group $b$, the mean NIHSS score decreased from $9.79 \pm$ 3.49 to $6.14 \pm 3.88$. Further, 24 (25\%), 35 (36.46\%), 20 (20.83\%), 10 (10.42\%), and 7 (7.29\%) patients showed complete recovery, remarkable progress, progress, no change, and worsening after treatment with argatroban, respectively. Taken together, the total effective rate was $82.29 \%$. In group c, the mean NIHSS score decreased from $11.62 \pm 2.28$ to $8.11 \pm 2.03$. Moreover, 4 (33.33\%), 4 (33.33\%), 2 (16.67\%), 1 (8.33\%), and 1 (8.33\%) patient showed complete recovery, remarkable progress, progress, no change, and worsening treatment with argatroban. Taken together, the total effective rate was $83.33 \%$.

Table 3

Therapeutic effect in the different groups.

\begin{tabular}{|c|c|c|c|c|c|c|c|c|c|c|}
\hline & $\mathbf{n}$ & $\begin{array}{l}\text { NIHSS } \\
\text { score }\end{array}$ & $\begin{array}{l}\text { NIHSS } \\
\text { score }\end{array}$ & Hemorrhage & $\begin{array}{l}\text { Complete } \\
\text { recovery }\end{array}$ & $\begin{array}{l}\text { Remarkable } \\
\text { progress }\end{array}$ & Progress & $\begin{array}{l}\text { No } \\
\text { change }\end{array}$ & Deterioration & $\begin{array}{l}\text { Total } \\
\text { effective }\end{array}$ \\
\hline & & $\begin{array}{l}\text { (before } \\
\text { therapy) }\end{array}$ & $\begin{array}{l}\text { (7d after } \\
\text { therapy) }\end{array}$ & $\mathbf{n}$ & n (\%) & n (\%) & n (\%) & $\mathrm{n}(\%)$ & n (\%) & rate $(\%)$ \\
\hline $\begin{array}{l}\text { Group } \\
\text { a }\end{array}$ & 72 & $\begin{array}{l}10.01 \pm \\
3.86\end{array}$ & $\begin{array}{l}7.92 \pm \\
4.45^{*}\end{array}$ & 0 & $\begin{array}{l}16 \\
(22.22)\end{array}$ & $\begin{array}{l}22 \\
(30.56 .)\end{array}$ & $\begin{array}{l}10 \\
(13.89)\end{array}$ & $\begin{array}{l}17 \\
(23.61)\end{array}$ & $\begin{array}{l}7 \\
(9.72)\end{array}$ & 66.67 \\
\hline $\begin{array}{l}\text { Group } \\
\text { b }\end{array}$ & 96 & $\begin{array}{l}9.79 \pm \\
3.49\end{array}$ & $\begin{array}{l}6.14 \pm \\
3.88^{*}\end{array}$ & 0 & $\begin{array}{l}24 \\
(25.00)\end{array}$ & $\begin{array}{l}35 \\
(36.46)\end{array}$ & $\begin{array}{l}20 \\
(20.83)\end{array}$ & $\begin{array}{l}10 \\
(10.42)\end{array}$ & $\begin{array}{l}7 \\
(7.29)\end{array}$ & 82.29 \\
\hline $\begin{array}{l}\text { Group } \\
\text { c }\end{array}$ & 12 & $\begin{array}{l}11.62 \pm \\
2.28\end{array}$ & $\begin{array}{l}8.11 \pm \\
2.03^{*}\end{array}$ & 1 & $\begin{array}{l}4 \\
(33.33)\end{array}$ & $\begin{array}{l}4 \\
(33.33)\end{array}$ & $\begin{array}{l}2 \\
(16.67)\end{array}$ & $\begin{array}{l}1 \\
(8.33)\end{array}$ & $\begin{array}{l}1 \\
(8.33)\end{array}$ & 83.33 \\
\hline Total & 180 & $10 \pm 4$ & $\begin{array}{l}6.98 \pm \\
3.88^{*}\end{array}$ & 1 & $\begin{array}{l}44 \\
(24.44)\end{array}$ & $\begin{array}{l}61 \\
(33.89)\end{array}$ & $\begin{array}{l}32 \\
(17.78)\end{array}$ & $\begin{array}{l}28 \\
(15.56)\end{array}$ & $\begin{array}{l}15 \\
(8.33)\end{array}$ & 76.11 \\
\hline
\end{tabular}

Group a: TT<40; group b: 80 $\geq \mathrm{TT} \geq 40$; group c: TT $>80$. $* p<0.05$, compared with NIHSS score before therapy. n: number

None of the patients showed severe systemic or symptomatic intracerebral bleeding. Hemorrhagic infarction developed in 1 patient in group c; however, the patient's symptoms did not worsen.

\section{Discussion}

Most patients with AIS cannot reach the hospital within six hours of symptom onset, and therefore there is a specific need for an effective and safe treatment for these patients, which is yet to be established. Argatroban, which is a synthetic peptidomimetic antithrombin agent, is the first clinical anticoagulant to exclusively target thrombin. The present study showed that IV argatroban therapy could prevent recurrence and progression of thrombosis in the infarcted area. A previous study showed that argatroban allowed safe anticoagulation in patients with AIS at 12 hours after the onset of symptoms without increasing intracranial hematoma [12]. In this study, we observed that IV argatroban treatment achieved good results and had a very low hemorrhagic risk (1/180 patient, $0.56 \%$ ). The median NIHSS score at admission $(10 \pm 4)$ decreased to $6.98 \pm 3.88$ after 7 days of therapy. Appropriate supportive care, including blood pressure, glucose, and lipid control, was paramount to achieving these results. Clinical symptom deterioration occurred in patients with severe stenosis of the middle or basal cerebral artery (10/15 patients, $66.67 \%)$.

Monitoring the status of anticoagulation is an important clinical parameter in patients with acute cerebral infarction during IV anticoagulant therapy. Although argatroban is commonly used in patients with AIS, there have only been a few studies on the relationship between the anticoagulation degree and clinical outcomes. A previous study recommended the analysis of the aPTT for argatroban. A steady-state aPTT was achieved after several hours of treatment, which should be approximately 1.5-3.0 fold increase of the aPTT baseline; however, it should not exceed 100 seconds (Kawai et al., 1996). In North America, a randomized, double-blinded, placebo-controlled study on direct thrombin inhibition in AIS showed that argatroban at each dose prolonged the aPTT without increasing symptomatic intracranial hemorrhage or major bleeding [12]. We measured the values of aPTT, PT, and TT in the peripheral 
blood of patients who received initial therapy for 24 hours. Further, we analyzed the relationship between blood coagulation biomarkers (APTT, PT, TT) and the therapeutic effect. Consistent with previous findings, we found a slightly increased aPTT prolongation after 24 hours of argatroban treatment; however, the value was only about $44 \%$ greater than the pretreatment level. Notably, plasma TT was significantly prolonged after 24 hours of argatroban treatment.

In our study, the patients were allocated to three groups according to the TT value, which indicated the anticoagulation degree. There was no significant inter-group difference in the total effective rate after IV argatroban. We observed high rates of positive outcomes in all three groups. However, the proportion of patients who completely recovered in group b and group c was significantly higher than that in group a. Given the hemorrhagic risk, we observed that when the TT value was 40-80 seconds, IV argatroban effectively improved the complete recovery rate without increasing the hemorrhage risk. In addition, we found that TT prolongation did not increase the total effective rate; however, it increased the chance of complete recovery and reduced the risk of worsening. Moreover, our results indicated that therapy with argatroban should be monitored using TT. TT assessment at 24 hours after initial therapy for confirming whether the desired therapeutic range and dose adjustment was achieved may be required to achieve the target TT. However, given the effect of individual variations on anticoagulant activity, it is difficult to determine the optimal argatroban dose to avoid hemorrhagic complications. Therefore, there is a need for large-scale randomized controlled trials to confirm our findings.

\section{Conclusion}

We found that IV argatroban could be an effective and safe treatment for patients with AIS at $>6 \mathrm{~h}$ after the onset of ischemic symptoms. Moreover, our findings suggest that TT could be used as an indicator for the evaluation of argatroban efficacy.

\section{Abbreviations}

IV: intravenous; AIS:acute ischemic stroke; aPTT:activated partial thromboplastin time; PT:prothrombin time; TT:thrombin time; NIHSS:National Institutes of Health Stroke Scale; CT:computed tomography; MRI:magnetic resonance imaging

\section{Declarations}

\section{Ethics approval and consent to participate}

The study was approved by ethic committee of the First Affiliated Hospital of Harbin Medical University, and the need for informed consent was waived owing to its retrospective design by the ethics committee of the First Affiliated Hospital of Harbin Medical University.

\section{Consent for publication}

Not applicable.

\section{Availability of data and materials}

The datasets used and analysed during the current study are available from the corresponding author on reasonable request.

\section{Competing interests}

The authors declare that they have no conflict of interest.

\section{Funding}

This work was supported in part by Postdoctoral Scientific Research Development Fund of Heilongjiang (LBH-Q18081 and LBHQ19159) and Higher Education Teaching Reform Project of Heilongjiang (SJGY20190425).

\section{Authors' contributions}


QQL was responsible for the study design, investigation, writing-original draft, conceptualization, and methodology. TJL mainly contributed to formal analysis, data curation, review writing, and editing. SSY revised and edited the manuscript for important intellectual content, as well as project administration and funding acquisition. All the authors approved the final version of the manuscript and agreed to be accountable for all study aspects.

\section{Acknowledgements}

Not applicable.

\section{References}

1. Escolar G, Bozzo J, Maragall S. Argatroban: a direct thrombin inhibitor with reliable and predictable anticoagulant actions. Drugs Today. 2006;42(4):223-36.

2. Furlan A, Higashida R, Wechsler L, Gent M, Rowley H, Kase CP, et al. Intra-arterial prourokinase for acute ischemic stroke. The PROACT II study: a randomized controlled trial. Prolyse in acute cerebral thromboembolism. JAMA. 1999;282(21):2003-11.

3. Imiya M, Matsuo T. Inhibition of collagen-induced platelet aggregation by argatroban in patients with acute cerebral infarction. Thromb Res. 1991;88(2):245-50.

4. Kawai H, Yuki S, Sugimoto J, Tamao Y. Effects of a thrombin inhibitor, argatroban, on ischemic brain damage in the rat distal middle cerebral artery occlusion model. J Pharmacol Exp Ther. 1996;278(2):780-5.

5. Keris V, Rudnicka S, Vorona V, Enina G, Tilgale B, Fricbergs J. Combined intraarterial/intravenous thrombolysis for acute ischemic stroke. AJNR Am J Neuroradiol. 2001;22(2):352-8.

6. Kobayashi S, Tazaki Y. Effect of the thrombin inhibitor argatroban in acute cerebral thrombosis. Semin Thromb Hemost. 1997;23(6):531-4.

7. Kobayashi S, Kitani M, Yamaguchi S, Suzuki T, Okada K, Tsunematsu T. Effects of an antithrombotic agent (MD-805) on progressing cerebral thrombosis. Thromb Res. 1989;53(3):305-17.

8. LaMonte MP, Nash ML, Wang DZ, Woolfenden AR, Schultz J, Hursting MJ, et al. ARGIS-1 Investigators. Argatroban anticoagulation in patients with acute ischemic stroke (ARGIS-1): a randomized, placebo-controlled safety study. Stroke. 2004;35(7):1677-82.

9. Marler J. Tissue plasminogen activator for acute ischemic stroke. N Engl J Med. 1996;33:1405-6.

10. Morris DC, Zhang L, Zhang ZG, Lu M, Berens KL, Brown PM, et al. Extension of the therapeutic window for recombinant tissue plasminogen activator with argatroban in a rat model of embolic stroke. Stroke. 2001;32(11):2635-40.

11. Urabe T, Tanaka R, Noda K, Mizuno Y. Anticoagulant therapy with a selective thrombin inhibitor for acute cerebral infarction: usefulness of coagulation markers for evaluation of efficacy. J Thromb Thrombolysis. 2002;13(3):155-60. 